\title{
Design and Thermal Analysis of High Power LED Light
}

\author{
Yavuz Sümer $^{*}$ (D), Onur Karaman² ${ }^{(D)}$, Ceren Karaman $^{3}$ \\ 'Sabancı University, Faculty of Engineering and Naturel Sciences, Department of Mechatronics, Istanbul, Turkey \\ ${ }^{2}$ Akdeniz University, Vocational School of Health Services, Department of Medical Imaging Techniques, Antalya, Turkey \\ ${ }^{3}$ Akdeniz University, Vocational School of Technical Sciences, Department of Electricity and Energy, Antalya, Turkey
}

\begin{abstract}
In the development of lighting technologies, light emitting diode (LED) technology plays an important role due to its high efficiency. LED lighting is the future of indoor and outdoor illumination solutions that all around the world there is a widespread transition to save energy and have better quality illumination via LED-based solutions. On other hand, cooling of high power LED is crucial factor to utilize LED in high performance. In addition, finned heat sink could not be efficient based on the its geometry and usage areas due to the powder, the rain and the effects of the muds. In this study, an un-finned heat sink LED armature consisting of aluminum sheet metal was designed using a computer-aided-design (CAD) program. Furthermore, manufacturing of the heat sinks from sheet metal plates with bending machines enables to increase variety of LED armatures cheaply according to design requirements. Then, the thermal analysis of the system was conducted for the case of natural heat convection under different electrical powers and ambient temperatures by a commercial finite element analysis (FEA) program: SolidWorks Simulation. As a result of the thermal analysis, the ultimate heat sink sizes were obtained to minimize the junction temperature of LED. Finally, the experimental studies were carried out to verify the feasibility of numerical solutions that they were in good agreement.
\end{abstract}

Keywords: LED, lighting, un-finned heat sink, thermal analysis, finite element analysis

\section{INTRODUCTION}

LED technology plays an important role due to its high efficiency. Lightening is responsible for $19 \%$ of total electrical energy consumption all around world according to the Internal Energy Agency [1]. LED lightening can be considered as a leading energy-saving solid-state lightening segment when compared to the conventional sources such as incandescent, fluorescent and high-intensity discharge (HID) lamps. LED lightening is the future of indoor and outdoor illumination solutions that there is a widespread transition to save energy and have better quality illumination via LED-based lightening [2].

LED is a semi-conductor circuit element that converts electric energy into light. The most important portions of the LED are the semiconductor material and the light emitting chip. This chip consists of $n$-type and $p$-type semiconductor layers. Also, an active substrate between the layers has electrical connection and junction. When DC current passed through the LED, electrons stimulate the active substrate, thereby light is generated [3]. The LEDs are the point light source; therefore, they are mostly equipped with the lenses to direct the light. Highly luminous LED chips created by combining multiple diodes in serial or parallel groups are used at every stage of our life. Compared to other lighting elements LED has considerably less energy consumption; because, the other lighting elements emit light by the principle of electric discharge or the heating of tungsten filament. However, LEDs give a large part of their energy as light. For example, in the same luminous flux (2600 lumen), the electrical power consumptions of the incandescent, HID, fluorescent and LED lamps are 150, 100, 42 and $25 \mathrm{~W}$, respectively [4]. Thus, LED lighting provides energy efficiency. Moreover, the LEDs do not contain any harmful gases whereas halogen lamps cause harmful greenhouse gas emissions.

On the other hand, the ambient temperature of the junction has a great effect on the LED performance. Operating the LED in high ambient temperatures can lead to overheating of the components, reducing luminous flux, shortening its useful life or finally causing failure [5].

A suitable heat sink is required to cool the LED to prevent the mentioned heating problems. This can be achieved by designing the heat sink considering LED working conditions. Finned type heat sinks are widely used for cooling by 
natural or forced convection. Based on the fin geometry and usage area, it may have considered as a disadvantageous when the powder, mud and rain effects are taken into consideration [6]. For example, the dust can clog the fins in metal factory or outside, subsequently, the rain or humidity can turn this dust into mud. Hence, the heat dissipation of LED armature becomes insufficient. Furthermore, cleaning of these fins is not easy and cheap as cleaning computer fans. Therefore, it can be suggested that an un-finned type heat sink is a solution for LED armatures whose working areas are dusty places.

In literature, many studies have been conducted on heat sinks for cooling of LED. In a LED recessed downlight development, Dong and Narendan [7] used finite-element methods and experimental studies to select fin type for reducing junction temperature. Dong [8] studied on the optimization of fins parameters such as numbers, arrangement and sizes of fins for cooling of rectangular heat dissipater. Wang and Li [9] developed a heat sink for LED armature by using forced convection method with a fan at room temperature instead of natural convection. Fengze et al. [10] investigated the thermal analysis of heat sinks types such as plate, in-line and staggered pin fin for cooling square LED light by using FEA. Tang et al [11] developed a phase change expansion assembly process for heat pipe heat sink to reduce the total thermal resistance of the LED module for reducing junction temperature and improving optical performance of LED conducting FEA and experiments. Moon et al. [12] conducted thermal analysis of $U$ shape flat heat pipe including fins by FEA and experimental for COB (chip on board) LED street light. Huang et al [13] developed a heat sink consisting of fins and grooved heat pipe by optimizing the heat sink materials and fin design via thermal analysis by using FEA. The work conducted by Hasan [14] the flow and heat transfer analysis of a finned and un-finned microchannel heat sink with nanofluids was investigated numerically. In the study of Usman et al. [15], the thermal analysis of finned and un-finned heat sinks including phase change materials were carried out by experimental works.

In this work, aluminum heat sink LED armatures excluding fins were developed for $30 \mathrm{~W}$ and $40 \mathrm{~W}$ power sources; and $25^{\circ} \mathrm{C}$ and $35^{\circ} \mathrm{C}$ ambient temperatures. In the design process, $\mathrm{U}$-cross sectional heat sink was designed. Due to the cost-effective nature of the manufacturing of these parts with laser cut and bending process without the need of mould, proper cooler-sized heat sinks were selected for each armature to enhance the LED efficiency. In the heat sink design process, the thickness and the sizes were selected as the parameters to iterate the design easily for CAD program (SolidWorks). Subsequently, thermal analysis was conducted for each power sources, and hot and normal environment conditions considering natural convection by a FEA program (SolidWorks Simulation). According to the design parameters, the analysis was iterated to optimize heat sink minimizing weight. Finally, the experimental studies were conducted to verify the simulation results.

\section{MATERIAL AND METHODS}

Herein, un-finned heat sinks were developed for 30W, 40W power and $25^{\circ} \mathrm{C}$ and $35^{\circ} \mathrm{C}$ ambient temperatures. Initially, the conceptual design of the $\mathrm{U}$ cross-sectional model was made. Then, the three dimensional (3D) geometry of heat sink was designed by SolidWorks based on variable design parameters including length, width and thickness to iterate design easily considering design requirements (such as size limits, junction and environment temperature, LED power). The thermal analysis of model was conducted by SolidWorks Simulation. The analyses were iterated for each design parameters by using Design Study module. In the light of the results, the optimal designs were selected for ideal junction temperate minimizing weight. These designs were manufactured by computer numerical control (CNC) cutting and bending machines. Finally, the experimental tests were conducted, and the simulation results were compared.

\subsection{Design Requirements}

The U cross-sectional sheet metal heat sinks were designed to be manufactured by $\mathrm{CNC}$ bending machines for manufacturing each designs cheaply and easily. In LED armature, Samsung COB LED (LC060D) was used [16]. Throughout the heat sink design, the following requirements have been considered:

- The ideal junction temperature of the LED is $85^{\circ} \mathrm{C}$. Considering the maximum $10 \%$ error, the junction temperature of design should not exceed $77.27^{\circ} \mathrm{C}$ in analysis.

- Heat sinks should have the cooling capacity for 30 $\mathrm{W}$ and $40 \mathrm{~W}$ power at $25^{\circ} \mathrm{C}$ and $35^{\circ} \mathrm{C}$ environmental conditions.

- Due to the assembly method via screws, the thickness of sheet metal should be at least $3 \mathrm{~mm}$. Also, for iteration of analysis with different thickness values, the standard aluminum sheet metal should be taken into consideration.

- Finally, the height of heat sink should be $6 \mathrm{~cm}$, and width and length should be at least $12 \mathrm{~cm}$ to assembly LED accessories (e.g., lens, drivers).

\subsection{Design}

In LED armature design, $U$ cross-sectional sheet metal part was developed by using SolidWorks. The square COB LED was attached to the center of the developed heat sink. Furthermore, thermal paste is needed to prevent cavity and air gaps between LED substrate and heat sink surface for increasing heat transfer. The schematic representation of the LED system and thermal resistance coupling was presented in Figure 1. 

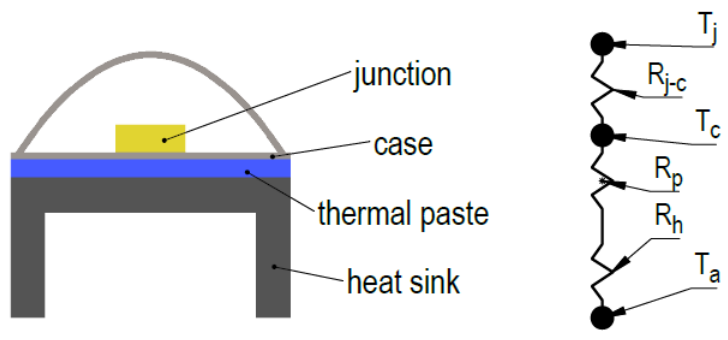

Figure 1. The example of LED assembly and resistance coupling

The heat generation in the junction is transferred to heat sink through case and thermal paste using heat conduction. As shown in Eq.1, the temperature of junction $\left(T_{j}\right)$ can be calculated from the case $\left(T_{c}\right)$ using power consumption $(P)$ in LED and thermal resistance $\left(R_{j-c}\right)$ between them:

$$
T_{j}=R_{j-c} \times P+T_{c}
$$

Eq.1 enables to control the junction temperature by thermocouple from case soldering point easily. When the thermal resistance of paste $\left(R_{p}\right)$ and heat sink $\left(R_{h}\right)$ are combined as $R_{p-h}$ and ambient temperature $\left(T_{a}\right)$ was considered, $T_{j}$ can be expressed as:

$$
T_{j}=\left(R_{j-c}+R_{p-h}\right) \times P+T_{a}
$$

Eq.2 summarizes the overall thermal analysis of heat sink design. The aim of the thermal analysis is to obtain the $T_{c}$; indeed, in background of analysis, $R_{p-h}$ was calculated, and Tc was obtained with boundary conditions including $\mathrm{P}$ and $T_{a}$. Thus, $T_{j}$ can be estimated according to Eq.1 using $R_{j-c}$ and $P$ values, and finally $T_{c} . R_{j-c}$ value was provided from COB LED datasheet as 0.24 [17].

The ideal junction temperature is $85^{\circ} \mathrm{C}$ (maximum operational temperature was $150^{\circ} \mathrm{C}$ ). Regarding $10 \%$ error, the optimum junction temperature was set as $77.27^{\circ} \mathrm{C}$. For $30 \mathrm{~W}$ power, $T_{c}$ was found as $70.07^{\circ} \mathrm{C}$ $\left(T_{c}=77.27^{\circ} \mathrm{C}-0.32\left({ }^{\circ} \mathrm{C} / \mathrm{W}\right) \times 30 \mathrm{~W}\right)$. For $40 \mathrm{~W}$ power, $T_{c}$ was found as $67.67^{\circ} \mathrm{C}\left(T_{c}=77.27^{\circ} \mathrm{C}-0.32\left({ }^{\circ} \mathrm{C} / \mathrm{W}\right) \times 40 \mathrm{~W}\right)$. Thermal paste with a thermal conductivity of $8 \mathrm{~W} / \mathrm{m}^{0} \mathrm{~K}$ (MasterGel Pro) [18] was integrated into the model at 100 $\mu$ thickness. The conceptual design was initially conducted based on the variable design parameters as thickness, width and length as shown: For the optimization of thermal analysis, these variables were used to iterate analysis for different sizes.

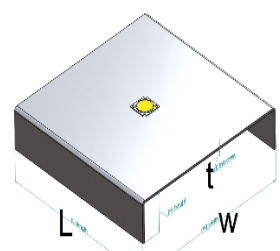

Figure 2. Conceptual design of the heat sink

\subsection{Analysis}

The thermal analysis of the heat sink was conducted by using
SolidWorks Simulation software. The aluminum sheet metal (6063-T6) with $209 \mathrm{~W} / \mathrm{m}^{0} \mathrm{~K}$ was used for the heat sink. The thermal paste was mounted $(0.1 \times 28 \times 28 \mathrm{~mm})$ between LED substrate and in the center of area $(L \times w)$. Eight main conditions $(C)$ existing for thermal analysis based on Power $(P)$, ambient Temperature $\left(T_{a}\right)$ and thickness $(t)$ were listed in Table 1.

Table 1. Main conditions depending on $P, T_{a}$ and $t$ parametres

\begin{tabular}{|c|c|c|c|c|c|c|c|c|}
\hline $\mathrm{P}$ & \multicolumn{4}{|c|}{$30 \mathrm{~W}$} & \multicolumn{4}{c|}{$40 \mathrm{~W}$} \\
\hline$T_{\boldsymbol{a}}$ & \multicolumn{2}{|c|}{$25^{\circ} \mathrm{C}$} & \multicolumn{2}{|c|}{$35^{\circ} \mathrm{C}$} & \multicolumn{2}{|c|}{$25^{\circ} \mathrm{C}$} & \multicolumn{2}{c|}{$35^{\circ} \mathrm{C}$} \\
\hline $\mathrm{t}$ & $3 \mathrm{~mm}$ & $4 \mathrm{~mm}$ & $3 \mathrm{~mm}$ & $4 \mathrm{~mm}$ & $3 \mathrm{~mm}$ & $4 \mathrm{~mm}$ & $3 \mathrm{~mm}$ & $4 \mathrm{~mm}$ \\
\hline $\mathrm{C}$ & 1 & 2 & 3 & 4 & 5 & 6 & 7 & 8 \\
\hline
\end{tabular}

Firstly, an arbitrary length and width were selected. For example, for Condition-1 $\left(C_{1}: \mathrm{P}=30 \mathrm{~W}, T_{a}=25, t=3 \mathrm{~mm}\right)$ length $(L)$ and width $(w)$ was selected as $15 \times 15 \mathrm{~cm}$. Considering natural convection, the $T_{c}$ was found $74.77^{\circ} \mathrm{C}$ higher than ideal temperature $\left(70.07^{\circ} \mathrm{C}\right)$. Then, both sizes were obtained as $20 \times 20 \mathrm{~cm}$ via incremental of $5 \mathrm{~cm}$, followed by the analysis was iterated and $T_{c}$ was found as $62^{\circ} \mathrm{C}$ lower than ideal temperature. Now, an optimization is needed by using Design Study module within these sizes $(15 \times 15 \mathrm{~cm}$ and 20 $\times 20 \mathrm{~cm}$ ) via incremental of each sizes (such as $1 \mathrm{~cm}$ ). There are six values for each sizes as $(15,16,17,18,19,20 \mathrm{~cm})$. When each values were expressed as $\left(L_{i}, w_{j}\right)_{i, j=1-6}$, there are $36(6$ $\times 6)$ possible scenarios for each other $(L, w)$ as depicted in Table 2. For example, $S_{2}$ means the iteration of analysis with $L_{1}$ and $w_{2}$ values. Similarly, for each condition $\left(C_{1}: C_{8}\right) 36$ scenario was conducted with different $L$ and $w$ sizes.

Table 2. Possible scenarios table based on $w$ and $L$ variables

\begin{tabular}{|c|c|c|c|c|c|c|}
\hline $\mathrm{L} / \mathrm{W}$ & $\mathrm{w}_{1}$ & $\mathrm{w}_{2}$ & $\mathrm{w}_{3}$ & $\mathrm{w}_{4}$ & $\mathrm{w}_{5}$ & $\mathrm{w}_{6}$ \\
\hline $\mathrm{L}_{1}$ & $\mathrm{~S}_{1}$ & $\mathrm{~S}_{2}$ & $\mathrm{~S}_{3}$ & $\mathrm{~S}_{4}$ & $\mathrm{~S}_{5}$ & $\mathrm{~S}_{6}$ \\
\hline $\mathrm{L}_{2}$ & $\mathrm{~S}_{7}$ & $\mathrm{~S}_{8}$ & $\mathrm{~S}_{9}$ & $\mathrm{~S}_{10}$ & $\mathrm{~S}_{11}$ & $\mathrm{~S}_{12}$ \\
\hline $\mathrm{L}_{3}$ & $\mathrm{~S}_{13}$ & $\mathrm{~S}_{14}$ & $\mathrm{~S}_{15}$ & $\mathrm{~S}_{16}$ & $\mathrm{~S}_{17}$ & $\mathrm{~S}_{18}$ \\
\hline $\mathrm{L}_{4}$ & $\mathrm{~S}_{19}$ & $\mathrm{~S}_{20}$ & $\mathrm{~S}_{21}$ & $\mathrm{~S}_{22}$ & $\mathrm{~S}_{23}$ & $\mathrm{~S}_{24}$ \\
\hline $\mathrm{L}_{5}$ & $\mathrm{~S}_{25}$ & $\mathrm{~S}_{26}$ & $\mathrm{~S}_{27}$ & $\mathrm{~S}_{28}$ & $\mathrm{~S}_{29}$ & $\mathrm{~S}_{30}$ \\
\hline $\mathrm{L}_{6}$ & $\mathrm{~S}_{31}$ & $\mathrm{~S}_{32}$ & $\mathrm{~S}_{33}$ & $\mathrm{~S}_{34}$ & $\mathrm{~S}_{35}$ & $\mathrm{~S}_{36}$ \\
\hline
\end{tabular}

The heat sink design was symmetrical concerning mid-planes. By the way, the analysis was conducted for the quarter part of the geometry as illustrated in Figure 3. Note that the one-quarter heat power should be applied.

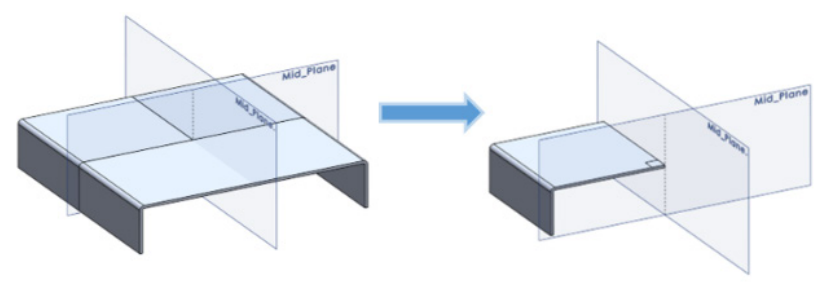

Figure 3. Quarter geometry of the heat sink

Mesh structure of geometry is needed to solve the mathematical model by the finite element method. The transformation of full model to quarter model enables to reduce the mesh elements; thus, symmetrical boundary condition increases the computational efficiency. As shown in Figure 4, 
the tetrahedral solid mesh was used in $1.5 \mathrm{~mm}$ element size for each solid parts.

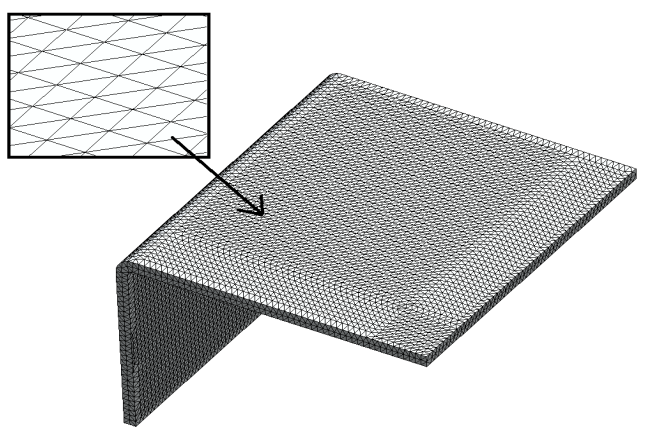

Figure 4. Mesh structure of the geometry

Furthermore, mesh converge is an important issue to obtain accurate simulation results. For this, the element size was decreased by half until the temperature variation ratio between two sequential simulations was found to be under $0.01 \%$. For instance, in $C_{1}$ condition simulation, while the size, the number of elements and the temperatures were 6 , 3 and $1.5 \mathrm{~mm}$, and 2049, 12052 and 66544, the temperature was found $69.5207^{\circ} \mathrm{C}, 69.5087^{\circ} \mathrm{C}$ and $69.5071^{\circ} \mathrm{C}$, respectively. As a result, the final temperature was obtained with $0.002 \%$ variation ratio. Similarly, mesh converge of each simulation was implemented.

The thermal analysis of the heat sink for eight conditions and 36 scenarios per condition were conducted. Based on the ideal case temperature, the optimal designs were selected within $\pm 0.5 \%$ temperature variation rate considering the least weight from Figure 5.

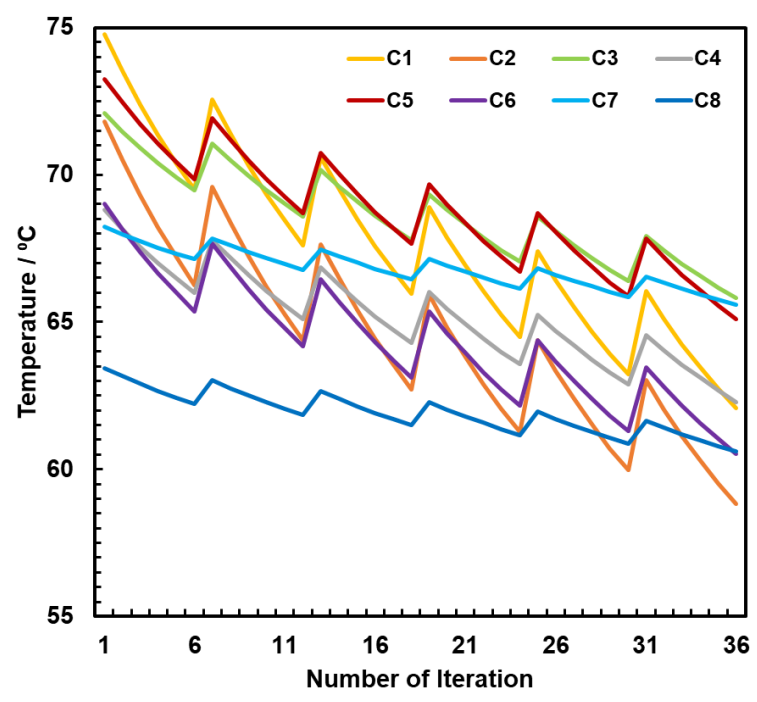

Figure 5. Iterative analysis results for optimization

\subsection{Experimental}

As obtained sizes from thermal analysis, each heat sinks was manufactured for each conditions. For $30 \mathrm{~W}$ and $40 \mathrm{~W}$ power LED lighting, $54 \mathrm{~V}, 555 \mathrm{~mA}$ and $740 \mathrm{~mA}$ dimmable LED driver was used, respectively. The ambient temperatures were sustained for $25^{\circ} \mathrm{C}$ and $35^{\circ} \mathrm{C}$ steady temperatures by heating cabin (Figure 6). Afterwards, all of $T_{c}$ values were measured with thermocouples until temperature difference varies below $1 \%$.

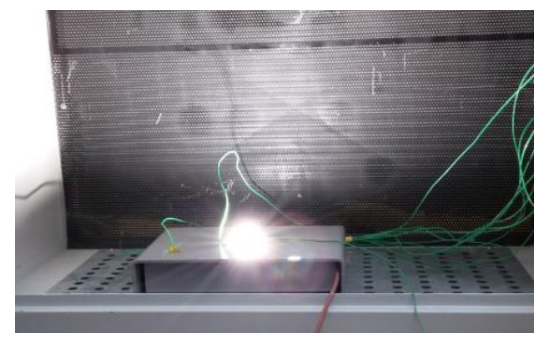

Figure 6. Experimental setup

\section{RESULTS AND DISCUSSIONS}

In lighting armatures, COB LEDs, which consist of multiple finite LED diodes on a single board surface, are preferred due to its compact size and high power capacity. Furthermore, its small chip luminescence application enables to use it with a single lens to ensure protection from dust and humidity in compact form instead of using SMD (Surface Mounted Device) or DIP (Dual In-line Package) LED array packing modules. However, this compactness leads to produce high heat flux per unit area. The junction temperature of COB LEDs is a major factor to determine the operational performance. High junction temperatures decrease optical efficiency, color quality and useful lifespan. For this reason, the cooling of LED armature is vital design and analysis process. In the literature on passive (natural convection) and active (means forced air convection with fans) cooling studies, mostly finned heat sinks were developed and preferred; since, they have more heat dissipation capacity than un-finned types. Generally, the assumptions on experimental works were made according to laboratory conditions. But, in outdoor or hot-factory light applications the heat transfer efficiency of finned heat sinks (based on narrow channeled) might be reduced due to dust effects. In addition, a cup could be used to ensure sealing against dust with molds for heat sinks; yet, it leads to prevent air contact of inner heat sinks. To eliminate the above problems, un-finned flat U cross-sectional shaped heat sinks were suggested. In the suggested model, using a single COB LED and lens enables protection of electronic system without sealing all system against external effects. It should be noted that not only the exterior but also the interior surfaces of the heat sink encounter air. Moreover, thanks to the suggested aluminum thin sheet metals for heat sink design, cost-natural, and easy manufacturing opportunities in varying sizes for each power armatures can be accomplished.

In this work, four un-finned heat sinks were developed for $30 \mathrm{~W}$ and $40 \mathrm{~W}$ power, and $25^{\circ} \mathrm{C}$ and $35^{\circ} \mathrm{C}$ ambient temperatures. For this, the thermal analysis of $\mathrm{U}$ cross-sectional heat sink including single COB LED was completed for all conditions by SolidWorks Simulation. The optimization of the heat sink was implemented by (Design Study Module) iterative solution for each situation with various lengths and widths. Then, the optimal cooler design was determined ensuring ideal $T_{c}$ and minimum weight. According to the 
drawings of the selected designs, the heat sinks were manufactured by CNC cutting and bending machines. Finally, experimental studies were conducted and the simulation results were validated with experimental results.

The thermal analysis of each conditions was completed. Although it can be obtained relatively more compact sizes by means of $4 \mathrm{~mm}$ thickness heat sink, $3 \mathrm{~mm}$-thickness heat sink was preferred for sustaining minimum weight $\left(C_{1}\right.$, $C_{3}, C_{5}$, and $C_{7}$ ). The temperature distribution results were shown in Figure 7, respectively.

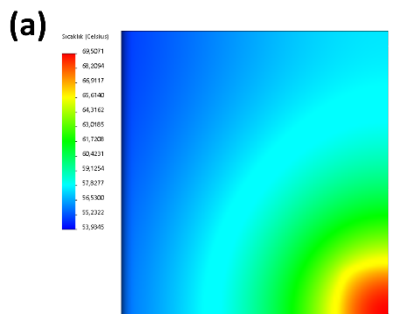

(c)

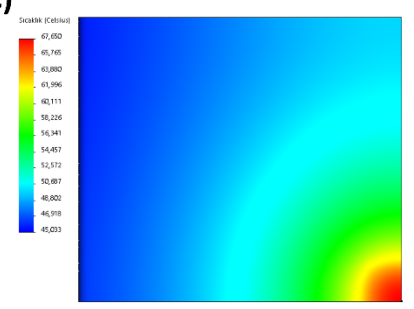

(b)

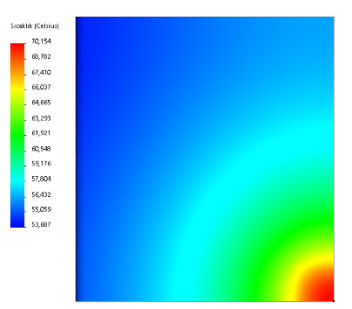

(d)

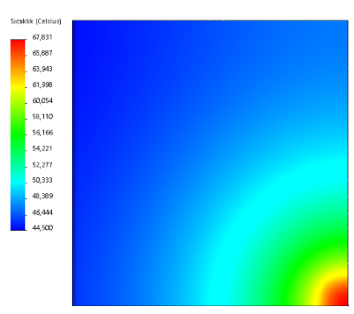

Figure 7. Temperature disturbances of heat sinks for (a) $30 \mathrm{~W}-25^{\circ} \mathrm{C}$, (b) $30 \mathrm{~W}-35^{\circ} \mathrm{C}$, (c) $40 \mathrm{~W}-25^{\circ} \mathrm{C}$ and (d) $40 \mathrm{~W}-35^{\circ} \mathrm{C}$ conditions

The maximum temperatures of developed heat sinks for $30 \mathrm{~W}-25^{\circ} \mathrm{C}, 30 \mathrm{~W}-35^{\circ} \mathrm{C}, 40 \mathrm{~W}-25^{\circ} \mathrm{C}$ and $40 \mathrm{~W}-35^{\circ} \mathrm{C}$ conditions were obtained as $69.51^{\circ} \mathrm{C}, 70.15^{\circ} \mathrm{C}, 67.65^{\circ} \mathrm{C}$ and $67.83^{\circ} \mathrm{C}$ at 66544, 110621, 126351 and 199869 mesh elements, respectively. The measured temperatures by thermocouples for these conditions were $72.3^{\circ} \mathrm{C}, 73.7^{\circ} \mathrm{C}, 70.1^{\circ} \mathrm{C}$ and $71.6^{\circ} \mathrm{C}$. As a result, the analysis results were calculated below $6 \%$ error ratio (maximum of 5.55\%) and the maximum junction temperature was found as $81.2^{\circ} \mathrm{C}$. In the light of the obtained results, four un-finned heat sinks not exceeding the ideal junction temperature $\left(85^{\circ} \mathrm{C}\right)$ were successfully developed.

\section{CONCLUSION}

The focus of this study was to develop an un-finned heat sink for COB LED application. The junction temperature is the important factor for LED efficiency that it was limited the maximum value of $85^{\circ} \mathrm{C}$ for four main situations $\left(30 \mathrm{~W}-25^{\circ} \mathrm{C}, 30 \mathrm{~W}-35^{\circ} \mathrm{C}, 40 \mathrm{~W}-25^{\circ} \mathrm{C}\right.$ and $40 \mathrm{~W}-35^{\circ} \mathrm{C}$ ). Firstly, the thermal analysis was conducted for different size parameters (such as length, width and thickness) and optimal design was obtained minimizing weight. Secondly, these designs were manufactured and the simulation results were validated through the experimental studies. Although the un-finned heat sink was suggested instead of finned types due to clogging disadvantage of fins according to usage areas, the temperature dissipation of the developed U-cross sectional model was not homogeneous relatively. This assessment might be addressed in future studies that relatively homogenous temperature distribution can be achieved for un-finned heat sinks with a new design and different cooling solutions. In conclusion, four heat sinks, which met all design requirements at the maximum junction temperature of $81.2^{\circ} \mathrm{C}$, were developed and applied to LED armatures.

\section{REFERENCES}

[1] Zhang, J., Xu, L., Wu, X., \& Qian, Z. (2011). A Precise Passive Current Balancing Method for Multioutput LED Drivers. IEEE Transactions on Power Electronics, 26(8), 2149-2159. https://doi.org/10.1109/ tpel.2010.2104332

[2] Khan, T. Q.,Bodrogi, P., Vinh, Q. T., \&Winkler, H. (Eds.). (2015). LED lighting: Technology and perception. John Wiley\&Sons.

[3] Krames, M. R., Shchekin, O. B., Mueller-Mach, R., Mueller, G. O., Zhou, L., Harbers, G., \&Craford, M. G. (2007). Status and Future of High-Power Light-Emitting Diodes for Solid-State Lighting. Journal of Display Technology, 3(2), 160-175. https://doi.org/10.1109/ jdt.2007.895339

[4] Pimputkar, S., Speck, J. S., Den Baars, S. P., \& Nakamura, S. (2009). Prospects for LED lighting. Nature Photonics, 3(4), 180-182. https:// doi.org/10.1038/nphoton.2009.32

[5] Hui, S. Y., \& Qin, Y. X. (2009). A General Photo-Electro-Thermal Theory for Light Emitting Diode (LED) Systems. IEEE Transactions on Power Electronics, 24(8), 1967-1976. https://doi.org/10.1109/ tpel.2009.2018100

[6] Ye, H., \& Zhang, G. (2011). A review of passive thermal management of LED module. Journal of Semiconductors, 32(1), 014008. https:// doi.org/10.1088/1674-4926/32/1/014008

[7] Dong, T., \& Narendran, N. (2009). Understanding heat transfer mechanisms in recessed LED luminaires. In I. T. Ferguson, C. Hoelen, J. Jiao, \& T. Taguchi (Eds.), Ninth International Conference on Solid State Lighting. SPIE. https://doi.org/10.1117/12.829902

[8] Dong, T. (2010). An analysis of heat transfer in LED luminaires. Rensselaer Polytechnic Institute.

[9] Wang, R., \& Li, J. (2010). A Cooling System with a Fan for Thermal Management of High-Power LEDs. Journal of Modern Physics, 01(03), 196-199. https://doi.org/10.4236/jmp.2010.13029

[10] Hou, F., Yang, D., \& Zhang, G. (2011). Thermal analysis of LED lighting system with different fin heat sinks. Journal of Semiconductors, 32(1), 014006. https://doi.org/10.1088/1674-4926/32/1/014006

[11] Tang, Y., Chen, Q., Guan, W., Li, Z., Yu, B., \& Yuan, W. (2017). Thermal analysis of an LED module with a novelly assembled heat pipe heat sink. Journal of Central South University, 24(4), 921-928. https:// doi.org/10.1007/s11771-017-3494-9

[12] Moon, S. H., Park, Y. W., \& Yang, H. M. (2017). A single unit cooling fins aluminum flat heat pipe for $100 \mathrm{~W}$ socket type COB LED lamp. Applied Thermal Engineering, 126, 1164-1169.

[13] Huang, D. S., Chen, T. C., Tsai, L. T., \& Lin, M. T. (2019). Design of fins with a grooved heat pipe for dissipation of heat from high-powered automotive LED headlights. Energy Conversion and Management, 180, 550-558.

[14] Hasan, M. I. (2014). Investigation of flow and heat transfer characteristics in micro pin fin heat sink with nanofluid. Applied thermal engineering, 63(2), 598-607.

[15] Usman, H., Ali, H. M., Arshad, A., Ashraf, M. J., Khushnood, S., Janjua, M. M., \&Kazi, S. N. (2018). An experimental study of PCM based finned and un-finned heat sinks for passive cooling of electronics. Heat and Mass Transfer, 54(12), 3587-3598. https://doi.org/10.1007/ s00231-018-2389-0 
[16] Sahbaz, M., Kentli, A., \&Koten, H. (2017). Thermal analysis and optimization of high power led armature. Thermal Science, 00, 238-238. https://doi.org/10.2298/tsci170704238s

[17] COB D-Gen.2 Data Sheet https://cdn.samsung.com/led/file/resource/2020/07/Data_Sheet_COB_D_Series_Gen.2_Rev.2.5.pdf Accessed on 2020-10-21.

[18] https://www.coolermaster.com/catalog/coolers/thermal-grease/ new-mastergel-pro/Accessed on 2020-10-21. 